\title{
Design of Power Marketing System Based on JavaEE
}

\author{
Fan Liu, Xiaoxiao Shu and Yongchao Luo \\ State Grid Jiangxi Electric Power Research Institute, Jiangxi Nanchang 330096
}

\begin{abstract}
Keywords: Power marketing; J2EE components; Data warehousing
\end{abstract}
\begin{abstract}
At present, with the increasing demand of electric power resources, the power marketing management becomes more and more complicated, and new requirements of power market management are put forward. According to the current status of the development of electricity market, it will be very important for the development of power marketing market to establish a sound power marketing strategy. This paper makes an in-depth analysis of the power management information system of power supply enterprises. At the same time, the management of power marketing at home and abroad is also discussed, and the existing management system and power demand of power supply enterprises are investigated deeply, especially the functional requirements and non-functional requirements study for the module inside system. The system design is finished from system module division, system module function, system data design and so on. The system uses the more popular Java development tool platform to achieve J2EE architecture as based framework using $\mathrm{J} 2 \mathrm{EE}$ components.
\end{abstract}

\section{Introduction}

The current power marketing system has a lot of problems, including: when the technology adopted by the system falls behind, it cannot meet the requirements of customers and enterprises; marketing business is composed of some subsystems, and each subsystem cannot communicate and share the information and so on. It's the inevitable choice of power enterprises to design and develop new and advanced marketing system that can integrate multiple businesses. Most of the power marketing systems in the past adopt client terminal/server, namely $\mathrm{C} / \mathrm{S}$ access mode. When there are too many connections under $\mathrm{C} / \mathrm{S}$ mode, it will cause the performance decreasing fast, taking up more resource and the responding time becomes slow; the client is connected with the server directly, but the security is poor, which has higher demand for the performance of the client; the client needs to be reinstalled for any modification of $\mathrm{C} / \mathrm{S}$ program on the server; the interface of $\mathrm{C} / \mathrm{S}$ is rigid and not very beautiful.

With the gradual development of Web applications, the application system uses browser as the presentation carrier of application interface, which has been gradually acknowledged and accepted. Under B/S mode, hierarchical structure is adopted, and superior performance can be achieved with distributed task processing and multi-client concurrent; B/S mode can be accessed only with a browser; B/S program modification can realize updating all the clients' program only by re-deployment on client terminal; the factors diversity of browser page under B/S system structure makes system interface more beautiful. In general, B/S based power marketing system is more in line with the current application environment and technology trends. At the same time, with the development of J2EE and the development and maturity of Struts, the marketing system based on $\mathrm{J} 2 \mathrm{EE}$ and Struts technology application B/S access mode has become popular system construction program in the power companies.

\section{Key Technology of J2EE}

EJB Components. EJB is actually a set of norms of Sun in J2EE, and it is stipulated that a series of API is used to transfer EJB concept into EJB products. When the EJB concept is transferred into EJB products, API can be used to replace. The problem to be solved in the container part mainly includes directory access, distributed management, security management, persistence management and computing pool management. The component section is primarily responsible for application 
logic. EJB technology defines a set of reusable components such as enterprise Bean. Programmers can use these components to build distributed applications like building blocks. When you write the code, these components are combined into the EJB module, each module has one or more enterprise beans, with some configuration parameters, and finally enterprise Bean can be deployed inside EJB container platform and get the Home interface of Bean from the inside of the container to locate the Bean. Thus, an instance of Bean can be achieved from the inside of the container. The Bean customer can be called through the client.

JSP Technology. JSP (Java Server Pages) is sponsored by Sun Micro Systems. Most companies will establish a complete set of dynamic web technology standards, in which JSP technology is similar to ASP technology and it is to insert Java program (Scriptlet) and JSP tag (tag) in the traditional web page HTML file $\left(^{*} . \mathrm{htm},{ }^{*}\right.$.html) into the in order to get a JSP file (*. Jsp). This technology is built on the Web technology and can be combined with a variety of application servers, and application servers, browsing servers and others can operate with it together. JSP specification is a Web server that can collaborate extensively among development tool vendors. At the same time, after receiving relevant customer access request, the Web server needs to implement the fragment in the page firstly, then the results in HTML format will be sent to the customer.

\section{Demand Analysis}

The core business of power marketing management is mainly composed by five aspects, including "meter reading, check and collection" and power purchasing and line loss indicators. The accounting and charges are mainly for electricity price, electricity quantity and electricity charge, and their relationship is relatively close; and meter reading, power purchasing and line loss have strong independence. To this end, we will divide power marketing management system into four core modules, including meter reading management, electricity price, electricity quantity and electricity charge management, power purchasing management, line loss management based on the functions. The overall structure of the system is shown in Fig. 1.

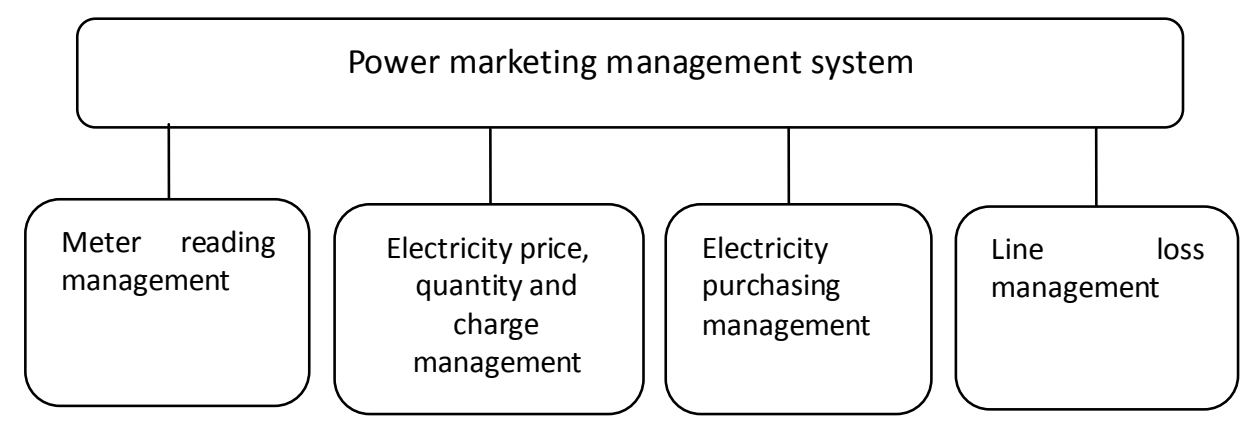

Figure 1. System overall structure 


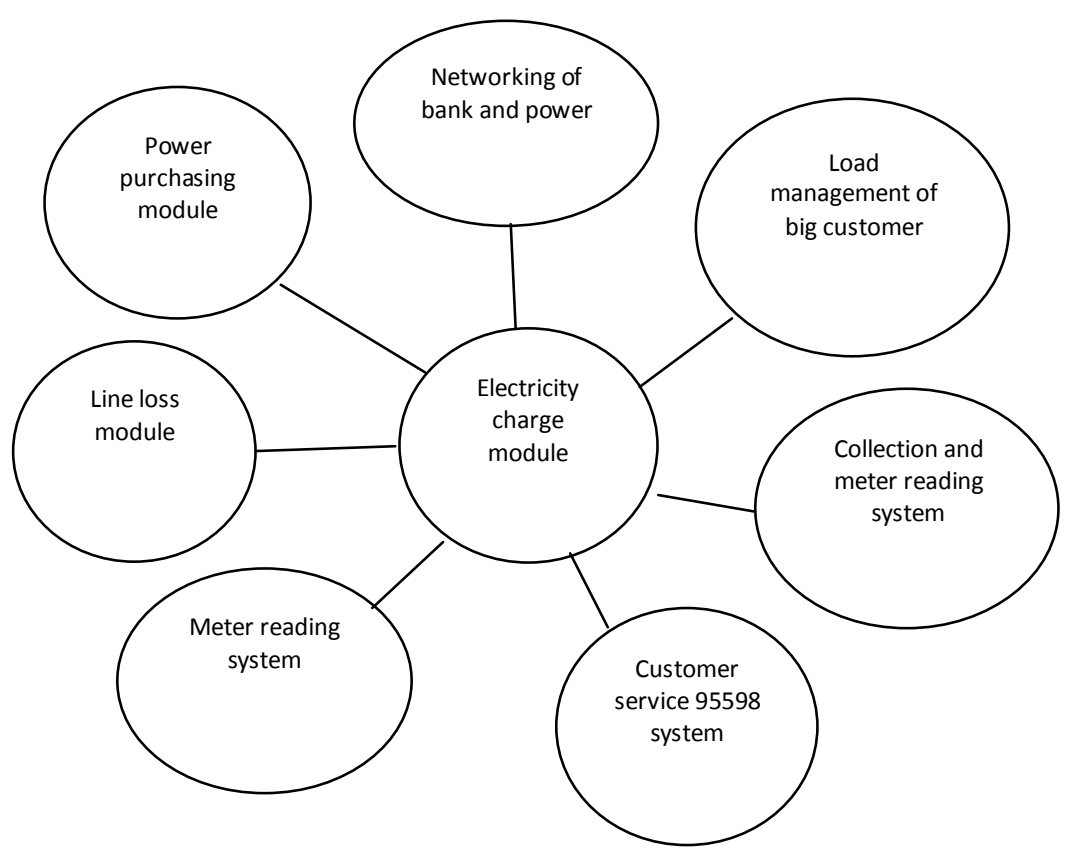

Figure 2. System function system structure chart

\section{Software Architecture of the System}

Electricity charge management module is the core module of the whole marketing system. It realizes each marketing business through close interaction with system interfaces, as shown in Fig. 2.

Electricity subsystem transfer arrearage information of the customer to the networking of bank and electricity, and it will inform the bank to send the payment information back to the marketing system after deducting the money.

The electricity charge subsystem transmits the daily charging information to financial system, which then reconciles with the bank's electricity charge capital.

Customer service 95598 system reads the customer's electricity charge information from electricity sub-system, and then transmits customer's business applications or telephone reports and other information to the marketing system for its follow-up business processing.

Collection and meter reading system reads meters by reading the user's meter reading file from marketing system, and sends meter information to the electricity sub-system to calculate the fee.

The tax control system reads the users' VAT invoice information from the marketing system and prints it, and returns the corresponding bill information to marketing system for archiving after printing.

The large customer load management system transmits the real-time electricity utilization information of the large customers to marketing system. When the user expands its business, it can detect the maximum load value of the line and provide decision support for the business expansion.

Marketing management system performs a unified measurement asset purchase plan. And metering device detection interface is integrated, including the seal interface, calibration table interface and so on.

The marketing system provides data such as customer information, arrears information, and industry expansion information to the auxiliary decision subsystem for relevant analysis.

\section{Data Warehouse Modeling Structure}

Relational data warehouse modeling based on star configuration, which is shown as Fig. 3. 


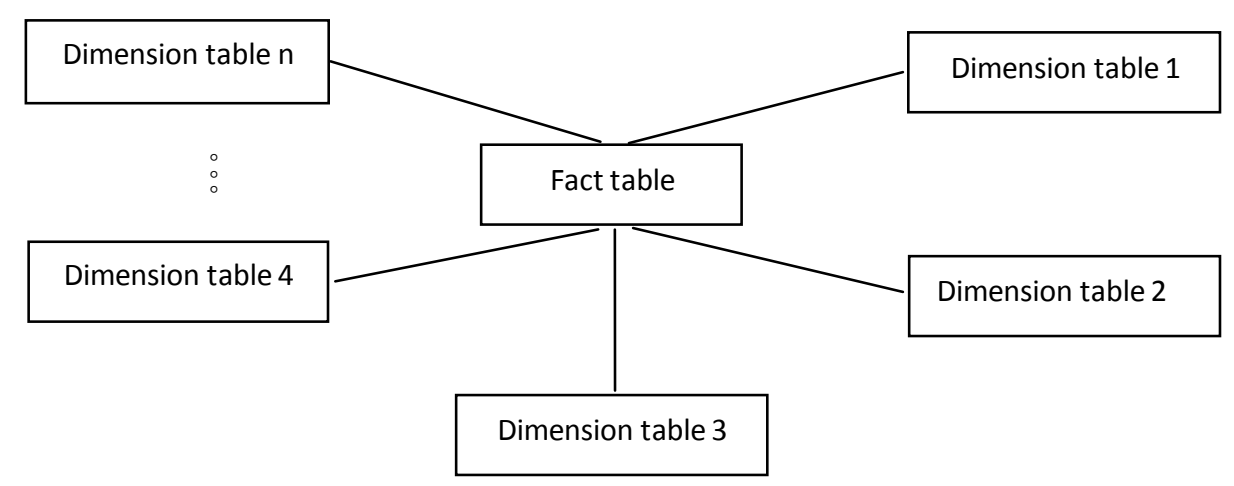

Figure 3. Relational data warehouse of star configuration

Fact table: A central table for storing basic and calculated index data. At the same time, the key value linking each dimension tables is put inside this table. It includes a large number of non-redundant data.

Dimension table: it is a set of object tables used to store information that defines indicator information, such as time, electricity category, and industry category. The dimension table contains descriptive information about the object.

This kind of star storage structure can facilitate the management or executive personnel understanding the business operations from multi-angle and multi-level. The requirements of storage structure by online transaction analysis can be met.

\section{Conclusion}

The power marketing system is a centralized reflection of customer-centric management model. It aims to provide convenient and quality service for the electric power customers, and sort out the original business process to extract the business standard, form a unified business standard, strengthen the marketing risk control and ensure the safety of electricity charge, through the means of information technology to promote the marketing business "standardized management, process operation", emphasizing the whole process monitoring in the management process. The establishment of information-oriented marketing management system not only ensures that the power marketing management business to be carried out smoothly, but also effectively enhances the level of enterprise information management. In this paper, the marketing management system is introduced in detail, from the feasibility and demand of the system, and then the system design and development, deployment architecture and software testing aspects are described comprehensively. Interface design is humanized, easy to operate, and the functional modules division is scientific and rational, which meets the needs of different roles.

\section{References}

[1] Y Zhang, Q Li, Design and implementation of power marketing system based on Flex[J]. Microcomputer \& Its Applications, 2013.

[2] J.X Long, T.M Wang, Implementation of business integrated platform for power marketing system[C]// The, IEEE International Conference on Information Management and Engineering. IEEE, 2010:460-465.

[3] X Zhao, Construction Analysis of Power Marketing Service System Based on Big Data[J]. Inner Mongolia Electric Power, 2016.

[4] W.W Lai, Power Marketing System Performance Optimization Analysis and Research[J]. Mechanical \& Electrical Engineering Technology, 2014. 
[5] R.Fan, On the Construction of "Technical Marketing System" in Power Marketing[J]. Value Engineering, 2014.

[6] C.Liu, H Zou and W Li, Research on Prediction and Decision-Making Policy in Power Marketing System[C]// International Conference on Computer and Management. IEEE, 2011:1-4.

[7] Y Zhao, Analysis on electricity market marketing strategy and power system planning balance[J]. Guizhou Electric Power Technology, 2014.

[8] L.U Xi-Jing, Construction of Intelligent Power Marketing Distribution Information System in Nanning Power Supply Bureau[J]. Guangxi Electric Power, 2011, 18(4):1879-90.

[9] Y.Y Liu, Application of Marketing and Distribution Integration System in Power Supply Bureau[J]. China Electric Power, 2012.

[10] Y Zhao, R.C Zhang, A power marketing data-mining system based on Web[J]. Journal of Henan Polytechnic University, 2010.

[11] J Liu, C.J Hu, Research on the Power Marketing Technique Supporting System Based on Semantic Web Services[J]. 2011.

[12]Z Liu, X Zu and X Chen, Sensitive Information Protection in Electric Power Marketing System Based on UCON Model[C]// Third International Conference on Mechanic Automation and Control Engineering. 2012:3075-3078. 